\title{
A Mandrágora Floresce na Primavera
}

\section{Mandrake Blooms in Spring}

Lidice Meyer Pinto Ribeiro (D)

Universidade Lusófona de Humanidades e Tecnologia, Faculdade de Ciências Sociais,

Educação e Administração, Departamento de Ciência das Religiões, Portugal

lidicemeyer@gmail.com

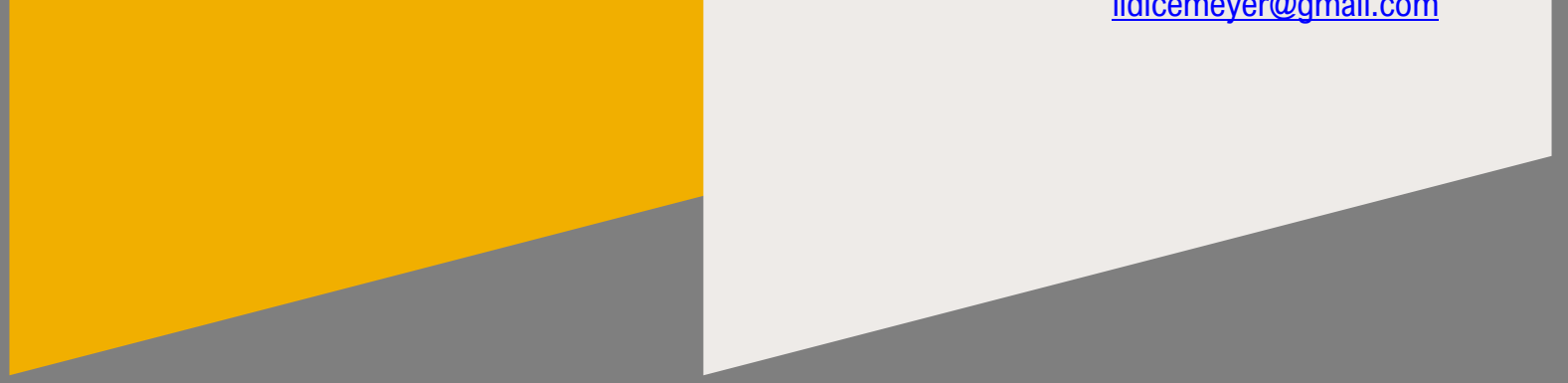


Quem busca uma boa revista académica com conteúdos sobre o binómio gênero e religião pode se dar por satisfeito com a Revista Mandrágora. Publicada semestralmente pelo Grupo de Estudos de Gênero e Religião Mandrágora do Programa de Pós-Graduação em Ciências da Religião da Universidade Metodista de São Paulo, Brasil, a revista conta com um corpo editorial formado por pesquisadoras renomadas encabeçado pela Profa. Dra. Sandra Duarte de Souza. Em suas quase três décadas de existência a Revista Mandrágora alcançou a maturidade que se espera para o debate de assuntos muitas vezes ainda delicados para a sociedade do século XXI. Suas diversas edições abordaram com seriedade e imparcialidade temas como aborto, direitos reprodutivos, o uso do corpo, políticas públicas, arte, fundamentalismos e direitos humanos, dentre outros.

Em sua última edição, publicada no primeiro semestre de 2021, volume 27, a Revista Mandrágora traz uma bela apresentação escrita pela Profa. Dra. Naira Pinheiro dos Santos e artigos que versam sobre assuntos diversos dentro do universo da religião e gênero. Usando de Hannah Arendt como sua porta voz, Naira dos Santos nos revela que apesar dos tempos sombrios em que vivemos à sombra de um mal invisível que invade corpos e casas, corroendo vidas por todo o planeta, precisamos reter a esperança de que tempos melhores virão. $E$ é dentro desta perspetiva que nos traz a belíssima citação de Pablo Neruda: "No entanto, há gente que acredita numa mudança, que tem posto em prática a mudança, que tem feito triunfar a mudança, que tem feito florescer a mudança... Caramba!... A primavera é inexorável!" (Pablo Neruda).

Primavera! Tempo de renovação de vida e de preparo dos frutos. Esta é a temática do artigo que abre este último número e que tem como título "O Sagrado Feminino na Primavera Bíblica". Escrito sob o viés da antropologia bíblica, um campo de estudo ainda muito pouco explorado nos países lusófonos, que visa analisar o texto bíblico em seu sentido original através de aproximações com o conhecimento adquirido da cultura do Israel antigo e dos povos circunvizinhos. Pode-se dizer que 0 primeiro a realizar tal aproximação académica foi o teólogo e linguista Robertson-Smith (1846-1894) em seu primeiro livro "The Religion of the Semites" publicado em 1889. Com o reconhecimento da antropologia como campo científico ao fim do século XIX, seguindo sua forma de análise vieram os trabalhos de Hugh John Dunkinfield Astley (1856-1930), Robert Graves (1895-1985), Alexander Heidel (1907-1955), Raphael Patai (1910-1996), Edmund Leach (1910-1989) e Mary Douglas (1921-2007). Já nos países lusófonos podemos citar estudos os já falecidos Milton Schwantes (1946-2012), brasileiro, e Alcindo Costa (1936-1976), português. Retomando a trajetória interrompida destes pesquisadores, tenho desenvolvido há cerca de vinte anos pesquisas em antropologia bíblica, com especial enfoque nas áreas da magia e do sagrado feminino. E é sobretudo nesta última área que recai a temática do artigo que publico neste último número da Revista Mandrágora.

Compreendido como a ligação natural entre a mulher e a natureza e consequentemente ao sagrado e às divindades, já há alguns anos 0 sagrado feminino tem sido trazido à discussão seja pelo viés do feminismo, seja pelo viés das religiosidades espiritualistas. Pouco ou nada se trabalha sobre o sagrado feminino na religião cristã. A proposta do artigo "O Sagrado Feminino na Primavera Bíblica" é resgatar o valor do sagrado feminino no cristianismo 
através da antropologia bíblica. Deste modo, realiza-se um estudo pela corrente antropológica do estruturalismo dos textos bíblicos associando-os com os mitos das divindades femininas relacionadas à primavera cultuadas nas regiões limítrofes de onde 0 Israel antigo se desenvolveu. Innana, Isis, Perséfone, Deméter e Ártemis renascem através do resgate de suas histórias milenares fazendo-nos perceber as diversas sobrevivências de seus mitos no imaginário comum do povo judaico nascente e ainda sendo reconhecidas mesmo no século I E.C. Embora muitas vezes haja a percepção de que todo o protagonismo feminino nas narrativas bíblicas tenha sido ofuscado pela autoria masculina dos textos, uma leitura atenta acaba por revelar a presença e atuação feminina em todos os momentos cruciais para 0 desenvolvimento do povo judeu, com uma especial ênfase nos rituais da primavera. A relação entre a mulher e a fertilidade transparece nos eventos relacionados à primavera no Antigo e Novo Testamentos bem como sua associação simbólica com arquétipos da deusa-mãe e das deusas da primavera. Em toda a trama da história bíblica destaca-se a constância da face feminina de Deus, ruach, o sopro divino, que fecunda, gera vida onde antes só há desolação e morte. Assim como o sagrado feminino, o vento de Deus é selvagem e não se deixa domesticar pela vontade do homem, ele sopra onde e quando deseja. Assim também é a primavera. Quando menos se espera, as flores surgirão das rachaduras das calçadas e de todas as brechas que encontrarem. $E$ é dessa forma que a mensagem do Cristo-Messias se revela como fonte de vida e de esperança na espera de sua segunda vinda. Sim, como Naira dos Santos destaca na apresentação: "Contra todas as evidências, que parecem apontar que a morte é que traga a vida, a primavera resiste, floresce e revive, mesmo nas sementes adormecidas pelo inverno".
A edição de número 27 da Revista Mandrágora traz ainda mais cinco artigos e uma resenha. 0 artigo "Therīgāthā a primeira literatura feminina no budismo: possibilidades de diálogo com 0 erotismo na teopoética" de Nirvana de Oliveira Moraes Galvão de França e Tattiane Yu Borges Marques, é um delicioso resgate de uma antologia de poemas escritos pelas primeiras monjas budistas na Índia durante a vida do Buda histórico, que expressam de forma atemporal suas experiências religiosas e de fé. Da Índia do século V a.C. somos levados pelas mãos de Claudete Beise Ulrich e Vinicius Silva de Oliveira à tecnologia do século XXI, onde máquinas começam a ganhar rostos e/ou vozes em sua grande maioria femininas. Os autores inquerem sobre o que estaria por detrás desta tendência no artigo "Os/as robôs tem sexo? Uma análise a partir da categoria de gênero a respeito da representação de mulheres em máquinas". Fazendo associações com imagens arquetípicas e mitológicas, conclui-se que a atual relação humano-religião-tecnologia se manifesta na tentativa de reproduzir nas máquinas, IAs e robôs, um modelo de mulher idealizada que correspondente a "uma mulher silenciada, privada de sentimentos próprios, de vontades e do prazer sexual, sujeitas exclusivamente à vontade dos homens". Após a reflexão futurista no viés da crítica feminista, viajamos novamente ao passado pelo texto "Costura de prazeres e requebros: a insurgência e atualidade de Filipa de Sousa", de José Pascoal Mantovani e Nathalia Magalhães Vincentin. Neste artigo analisa-se a história de uma costureira do século XVI no Brasil colônia, alvo da inquisição religiosa por suas práticas sexuais homossexuais. 0 desconhecimento do Tribunal do Santo Ofício dos termos apropriados para suportar o julgamento de seus supostos crimes faz de Filipa de Sousa um caso de estudo relevante para a compreensão das relações entre a religião católica e a sexualidade no Brasil colônia. Uma relação que em muitos aspectos ainda se faz segundo os 
mesmos padrões de controle e de valorização da heteronormalidade e da virgindade casta. É o que podemos ver nos dois próximos artigos publicados neste número da Revista Mandrágora. Kelly Caroline Noll da Silva, no artigo "Virgem", "heroica" e "mártir": análise da construção de um modelo de santidade feminina a partir do caso de Albertina Berkenbrock (Santa Catarina, 1952-1959)" denuncia como a imagem de uma menina estuprada e morta aos 12 anos de idade foi sendo reconstituída através da imprensa como uma virgem-mártir para que se encaminhasse seu pedido de beatificação em 1952 pela Arquidiocese de Florianópolis. Um modelo de santidade contruído para reafirmar um catolicismo conservador que também transparece no último artigo: "Gelo no pênis, exorcismo e medo": gênero, sexualidade e religião em relatos de seminaristas e padres homossexuais", em que Eliane Rose Maio e Jean Pablo Guimarães Rossi analisam entrevistas realizadas com padres assumidamente homossexuais que relatam um processo constante de vigilância, culpabilização, privação, punição, expulsão, separação e silenciamento como mecanismos de contenção e de sujeição dos desejos e práticas sexuais. Como fechamento da trajetória traçada nesta edição temos a resenha do livro "Lesbian, Gay, Bisexual and Transgender Christians: Queer Christians, Authentic Selves", de Bronwyn Fielder e Douglas Ezzy, realizada por Tainah Biela Dias.

A Revista Mandrágora cumpre mais uma vez sua importante função de dar a voz a autores que ousam relacionar as temáticas de gênero e religião, abrindo espaço para a reflexão sobre temas delicados e sensíveis, lançando sementes de análise crítica que no devido tempo, em chegada a primavera, desabrocharão para o diálogo aberto e sem preconceitos.

\section{Bibliografia}

Revista Mandrágora (2021). v. 27, n. 1. https://www.metodista.br/revistas/revistasims/index.php/MA

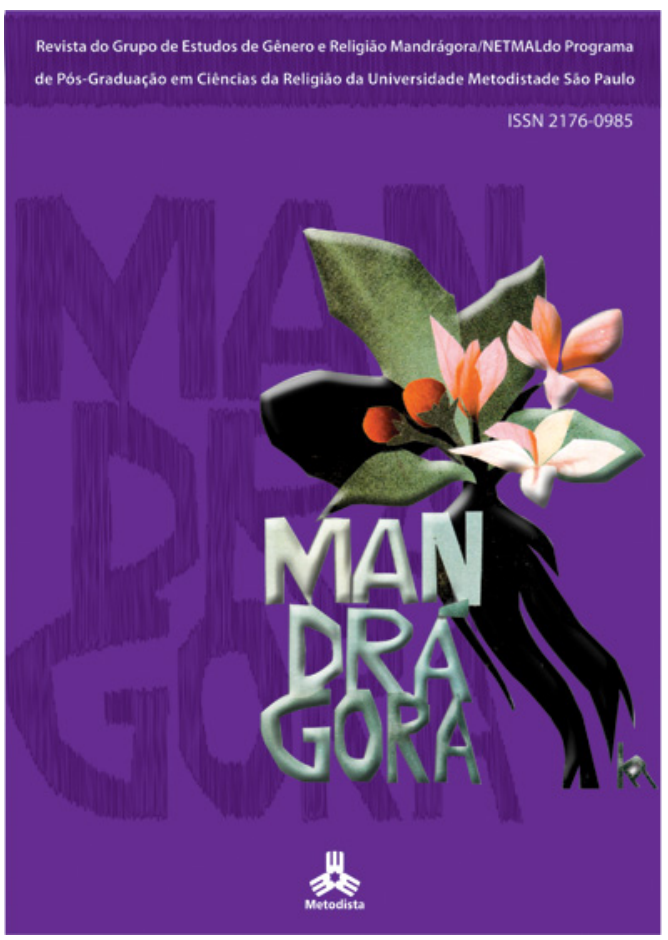

